\title{
National Smoke Abatement Society
}

\section{Meeting at Bristol}

\begin{abstract}
$\mathrm{T}^{\mathrm{H}}$ HE annual conference of the National Smoke Abatement Society was held in Bristol on September 20-21 under the presidency of Dr. H. A. de Voeux. Dr. A. G. Ruston summarised the work done with the late Prof. J. B. Cohen on the damage caused by smoke in the West Riding of Yorkshire. Animal, as well as vegetable, life suffers. Land exposed to acid atmosphere becomes deficient in lime, and cows grazing on such land yield milk also deficient in lime.

Dr. R. Lessing reviewed sources of atmospheric pollution, and advocated systematic surveys. The generation of electricity in large units, while diminishing total pollution, has resulted in the localised emission of exceptionally large quantities of acid flue gases, often in thickly populated areas. The concentration of fuel burning has the advantage of facilitating efficient utilisation and also the scientific treatment of the flue gases. Within a few years, two processes have been elaborated for the desulphurisation of flue gases, in the Battersea and Fulham Power Stations. The Fulham process has the advantage of producing no liquid effluent. Dr. Lessing estimates that both processes, when in full operation, will reduce the sulphur acids passed annually into the London atmosphere by 40,000 tons. The London gas companies already recover, during gas purification, sulphur equivalent to 55,000 tons of acid. It may be estimated that the public utilities
\end{abstract}

will eventually recover or remove 20 per cent of the sulphur present in the coal burnt in London.

Large power stations emitting flue gases at a high velocity may be an important source of grit and dust, which is an insidious but noxious polluting agent. Fortunately, the washing process also takes care of the grit and dust at the same time. Central heating of large buildings, institutions, blocks of flats is leading to analogous conditions of local atmospheric pollution on a smaller scale.

Hitherto, efforts to diminish atmospheric pollution have been due mainly to idealists possessing knowledge and vision but impotent to alter actual conditions. Those wielding political power, local and national, have been indifferent. Commercial interests have been passively or actively resistant. Conditions, however, change. Already it is recognised that smoke endangers air traffic, and may render a site ineligible for aerodromes. A recent report of an investigation conducted at Pittsburgh expressed the view that "Smoke is a major obstacle to the popularisation of aviation". Atmospheric pollution is largely responsible for the movement of urban population to the country, and this promotes 'ribbon development'. Smoke may make a district unsuitable or unattractive for new industries. The realisation of this by local authorities and chambers of commerce ought to engender a more active interest in ameliora. tive measures.

\section{Problems of Administration and Management}

$\mathrm{P}^{\mathrm{n}}$ ROBLEMS of amalgamation and decentralisation were discussed at Norwich on September 9 by the Department of Industrial Co-operation of the Economic Science and Statistics Section of the British Association. Mr. L. Urwick opened the discussion with a paper on executive decentralisation with functional co-ordination in which he emphasised the necessity for a technical approach to questions of organisation. After discussing the nature of responsibility, and its relation to authority and power, he pointed out that reasons of time and space as well as psychological factors were important influences making for decentralisation. The steady and inevitable growth of functional specialisation made imperative the clear distinction between executive and administrative or policy-making responsibility, as well as the co-ordination of functional methods, and the reconciliation of these two tendencies was the central problem in modern business organisation. Failure to recognise the nature of the difficulty might easily involve the failure of a business combination. When a new duty arose, Mr. Urwick insisted that the only ultimate solution was to define that duty and assign it to individuals, properly selected and suitably trained. He regarded it as inevitable that business organisation should evolve towards a true system of 'staff' positions and relationships as distinct from either 'line' or 'functional' positions, and organised staff training was accordingly essential.
Mr. T. G. Rose described some examples of decentralisation problems in small undertakings, particularly of the management difficulties arising with a head office in London and works in the provinces, or in financial control from London while management and manufacturing activities are carried on in the provinces, or again in the decentralisation of management in a group of rationalised small firms.

Dr. K. G. Fenelon discussed problems of centralisation and decentralisation in the management and administration of combines. A choice between these two alternatives in practice has usually been made on an empirical basis, and frequently following an initial centralisation, a complete reorganisation had been undertaken to achieve decentralisation on a scientific basis. Such a task of reorganisation involves the careful study of each of the different functions and activities and the determination of the most suitable organisation for each. This reorganisation accordingly involves three stages : first the bringing of all the threads into the hands of the central management for the study of the problems and procedure of the different units; secondly, comparative analysis of the varying activities, leading to standard practice ; and thirdly, the evolution of a process of decentralisation to give new elasticity.

Dr. Fenelon stressed the extent to which effective decentralisation depended not only on careful study 